\title{
A randomised controlled trial of psycho-educational interventions for reducing uncertainty and anxiety, and improving sexual functioning among gynaecological cancer patients in Hong Kong
}

Chow K. M. ${ }^{1}$, Chan, C. W. H. ${ }^{1}$, Choi, K. C. ${ }^{1}$, Siu, K. Y. ${ }^{2}$, Fung, H. K. S. ${ }^{3}$, \& Sum, W. M. ${ }^{3}$

${ }^{1}$ The Nethersole School of Nursing, The Chinese University of Hong Kong, Hong Kong S.A.R.

Department of Obstetrics and Gynaecology, Prince of Wales Hospital, Hospital Authority, Hong Kong S.A.R.

${ }^{3}$ Department of Obstetrics and Gynaecology, Queen Elizabeth Hospital, Hospital Authority, Hong Kong S.A.R. The work described in this study was fully funded by Health and Medical Research Fund (HMRF) from Food and Health Bureau, the Government of the Hong Kong Special Administrative Region (Project No. 13141551)

\section{Introduction}

(L) The diagnosis of gynecological cancer (GC) and the effects of related treatments have adverse effects to sexual functioning (Wilmoth \& Spinelli, 2000).

(4) Unpredictable disease outcomes and the complexity of cancer treatment also lead to uncertainty in gynecological GC patients.

(L) High levels of uncertainty are associated with high levels of anxiety, which may negatively impact on quality of life (Zhang, 2017).

(L) Psycho-educational interventions (PEI) for GC patients were found to have positive effects on sexual functioning and psychological outcomes (Chow et al., 2016).

\section{Purpose}

To implement a 4-session programme of psycho-educational interventions for GC patients in Hong Kong, and evaluate its effects on uncertainty, anxiety and sexual functioning.

\section{Result- Quantitative}

\section{Baseline characteristics $(n=202)$}

\begin{tabular}{|c|c|c|c|}
\hline Demographics & Mean \pm SD $/ \%$ (N) & Clinical Characteristics & Mean \pm SD $/ \%$ (N) \\
\hline Age (years) & $54.6 \pm 9.7$ & Type of cancer & \\
\hline Married & $66.8 \%(135)$ & Uterine cancer & $61.9 \%(125)$ \\
\hline Level of Education & & Cervical cancer & $16.3 \%(33)$ \\
\hline Secondary or above & $68.8 \%(139)$ & Ovarian cancer & $10.9 \%(22)$ \\
\hline Have children & $73.3 \%(148)$ & Stage of cancer : I & $55.0 \%(111)$ \\
\hline $\begin{array}{l}\text { Monthly Family Income } \\
<=H K \$ 19,999 \text { ( USD2548) }\end{array}$ & $56.9 \%(115)$ & $\begin{array}{l}\text { Type of treatment } \\
\text { Operation Only }\end{array}$ & $70.3 \%(142)$ \\
\hline
\end{tabular}

* No significant differences were found between the intervention and control groups

\section{Sexual Function at T2}

Mean scores of SVQ subscales

\begin{tabular}{|c|c|c|c|}
\hline Sample & Subscale & Intervention $(n=63)$ & Control $(n=75)$ \\
\hline \multirow{3}{*}{ 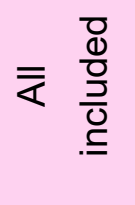 } & Intimacy & $4.7 \pm 12.4$ & $2.7 \pm 1.1$ \\
\hline & Global sexual satisfaction & $8.8 \pm 1.5$ & $8.8 \pm 1.5$ \\
\hline & Sexual interest & $1.5 \pm 0.8$ & $1.4 \pm 0.7$ \\
\hline \multirow{2}{*}{ 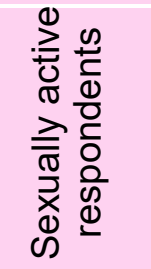 } & Vaginal changes & $\begin{array}{c}11.7 \pm 2.8 \\
(n=11)\end{array}$ & $\begin{array}{c}12.3 \pm 1.6 \\
(n=6)\end{array}$ \\
\hline & Sexual Functioning & $\begin{array}{l}8.6 \pm 1.7 \\
(n=13)\end{array}$ & $\begin{array}{c}8.4 \pm 1.6 \\
(n=8)\end{array}$ \\
\hline
\end{tabular}

$*$ No significant differences were found between the intervention and control groups

Single item analysis of the most prevalent sexual problems

\begin{tabular}{l|c|c|}
\hline SVQ items & $\begin{array}{c}\text { \% of Intervention } \\
\text { group }(n=63)\end{array}$ & $\begin{array}{c}\text { \% of Control } \\
\text { group }(n=75)\end{array}$ \\
\hline $\begin{array}{l}\text { Little or no interest in close physical } \\
\text { contact (a kiss and a cuddle) }\end{array}$ & 82 & 88 \\
\hline $\begin{array}{l}\text { Little or no close physical contact } \\
\text { with family and close friends }\end{array}$ & 79 & 93 \\
\hline Low or no sexual interest & 84 & 87 \\
\hline Not sexually active & & 79
\end{tabular}

$\wedge$ Sexually active respondents only, $n=46$ for the intervention group, $n=56$ for the control group I. Intervention group had significantly better performance in these items $(p<0.05)$

\section{Result- Qualitative}

을 All participants $(n=67)$ perceived the intervention as helpful.

으 They valued the psychological and informational support from nurses.

00 Majority of them perceived the number of sessions appropriate, some wanted to have extra sessions at longer-term follow up.

○0: They would recommend the PEI to other GC patients.

\section{Methods}

Design: Randomised controlled trial with a mixed-method design Study sites: 2 regional hospitals

Sample:

※ Newly diagnosed GC patients with surgery as the first-line treatment

* Over 18 years old

* Able to understand spoken Cantonese and read Chinese

Quantitative outcome measures (Chinese version):

※ Mishel's Uncertainty in Illness Scale (MUIS) (Taylor-Piliae \& Molassiotis, 2000) [T1 \& T2] * Anxiety subscale of Hospital Anxiety and Depression Scale (HADS) (Leung et al., 1999) [T1 \& T2

※ Sexual Function-Vaginal Changes Questionnaire (SVQ) (Chow et al., 2010) [T2]

Qualitative data collection: Semi-structured individual interviews 